\title{
DOCUMENTOS
}

\section{[Discurso del rector de la Universidad de Chile, Prof. Luis A. Riveros, al asumir su cargo, el viernes 3 de julio de 1998]}

Hace casi un siglo atrás, en esta sala, el Profesor Valentín Letelier argumentaba en su clase magistral sobre educación y sociedad, que la existencia de la Universidad de Chile era la consecuencia lógica de la madurez que había adquirido la nación chilena, puesto que la creación de Andrés Bello le había otorgado un instrumento para viajar permanente hacia el futuro, contribuyendo al progreso del país por medio de la creación y difusión del conocimiento, una base ciertamente segura para construir un sostenible progreso material e intelectual.

En esa consecuencia lógica, postulada al cabo de nuestros primeros cincuenta años de vida institucional, se encuentra inmersa la misión de nuestra Universidad de Chile. Confundida ella en el tiempo con la construcción de la República y con lo más caro del ideario nacional, ha sido la fuente sempiterna de inteligencia e ideas, que ha decorado la historia patria con sus más insignes hijos, y levantado enhiesto el nombre del país y el prestigio de su tradición de enseñanza en todos los confines del mundo.

La misión institucional consiste en crear y diseminar conocimiento para el desarrollo social, cultural, económico, tecnológico y político en nuestra patria. La ratificamos hoy, con plena conciencia de nuestras responsabilidades inherentes, y en el convencimiento absoluto de que el progreso de Chile se encuentra indisolublemente ligado a su Universidad de Chile.

Fue el mismo Rector Letelier quien afirmó que gobernar es educar. Un lema más tarde usado en su Gobierno por el ex-decano de la Facultad de Economía Industrial, don Pedro Aguirre Cerda. ¿Qué quiere decir eso?, ¿Cuáles son las implicancias de lo que parecería no ser más que un buen eslogan?

Al ser la Universidad de Chile un agente de progreso económico, social e intelectual, y al tener que estar ella indisolublemente ligada al Estado nacional por la naturaleza de su misión y su razón de ser Institucional, parece no caber duda respecto que, un Gobierno preocupado sobre la necesidad de un progreso sustentable, deberá ser proactivo para fundamentar el mismo en bases ciertas, llevando inevitablemente a la idea de que la educación es una responsabilidad prioritaria de Estado. Los días del mercado y de la modernización económica no desmienten este rol vital, insustituible, de una educación de calidad para todos, y de una universidad abierta a los mejores, con preocupación activa y calificada en la creación de conocimiento.

Queremos una Universidad de Chile con liderazgo en el mundo de la educación, particularmente de su ámbito público. S.E. El Presidente de la República se ha referido reiteradamente a los riesgos graves de que nuestra nación experimente una segunda frustración histórica en sus ímpetus de desarrollo económico, y la necesidad de prevenirlos desde el punto de vista de las acciones de Gobierno y de la actitud del sector privado. Pero no constituye una novedad afirmar que estas frustraciones derivan, al fin y al cabo, de la existencia de profundos desequilibrios del desarrollo que ocurre en distintos ámbitos de la sociedad. Hoy en día prevalecen significativas brechas distributivas y en el acceso al conocimiento; las desigualdades de oportunidad y condición, constituyen una semilla de inestabilidad, que el Gobierno ha advertido y 
que sabe muy bien se conecta en forma directa con la educación, con su calidad y con las posibilidades que ella permita distribuir mejor los beneficios del progreso.

Nos preocupa la educación pública chilena. Es nuestro mundo natural. Queremos asumir un claro liderazgo en ideas sobre esta materia. Estamos profundamente convencidos sobre nuestra misión como Universidad a este respecto. No se justificaría una Universidad de Chile nacional, laica y de alta excelencia académica, si no abordara con prioridad la tarea de ser propositiva en materia de tan vital importancia. Nos preocupa la educación universitaria estatal; creemos que las Universidades del Estado son más que meras productoras de profesionales, y que tienen una misión de reflexión y propuesta que la sociedad necesita, ante problemas a nivel país que adquieren complejidad y enormes influencias en el devenir futuro. Algunas operaran con estos problemas en el ámbito regional, o disciplinario específico que les compete; la Universidad de Chile debe hacerlo en el plano de los problemas nacionales, los cuales tienen que ser abordados con excelencia y como medio para que el Estado lleve adelante mejores políticas y promueva la crítica que lleva al progreso en las ideas y la organización social.

Por eso nos preocupa también que existan reglas y financiamientos adecuados para la tarea universitaria del Estado. No se trata sólo de alimentar las aspiraciones legítimas de una comunidad universitaria. Se trata más bien de pensar en un sistema que requiere un cambio fundamental para que cumpla efectivamente con las tareas que el país demanda en el ámbito de la formación profesional, de los programas de postgrado, de la investigación científica y de la creación artística, humanística y cultural. Hay también tareas privadas que se ligan a los intereses de un sector muy definido en el mundo universitario chileno, cuyo aporte debe ser valorado y respetado; pero hay también tareas públicas, ligadas indisolublemente a una Universidad de carácter nacional como la nuestra.

Creemos firmemente, como lo dijera el ex-rector Juvenal Hernández con motivo del centenario de nuestra Casa de Estudios, que el futuro de Chile está claramente ligado a la Universidad de Chile. Sabemos que vivimos años distintos, que existen otros desafíos y otros marcos que deben modelar nuestro desempeño como Institución. No le tememos a competir, ni tampoco a vincularnos, como lo hemos hecho, con el sector privado para poder así desarrollar nuestra tarea más efectivamente. Pero todo esto requiere también consolidar la investigación de largo plazo, desarrollar equipos de excelencia académica, sustentar las áreas de humanidades, ciencias sociales y artes, proteger la extensión artística y cultural, preocuparnos de muchas áreas necesarias que no son, por su naturaleza, una preocupación del sector privado ni abordables exclusivamente por la vía del mercado.

La Universidad de Chile y las universidades públicas precisan de más Estado para el desempeño de las tareas a que están llamadas. No podemos depender en forma predominante del financiamiento privado, ya que ello distorsiona el cumplimiento de nuestro papel en la sociedad chilena de hoy. Por eso, al asumir esta alta responsabilidad quiero ratificar el compromiso con nuestra misión institucional; el compromiso también de modernizar permanentemente nuestro quehacer y nuestras estructuras; la responsabilidad de seguir consolidando nuestra excelencia académica. Queremos que el Chile del mañana tenga a su Universidad de Chile, tal y como -y aún mejor- de la que nuestra generación recibió de sus antecesores. 
En ese esfuerzo, en esa tarea magnífica, seremos inclaudicables. No estamos dispuestos a transar la Universidad; no deseamos seguir con la deriva de una marea que nos conduce a un fin distinto de aquel que diseñaron nuestros fundadores, y distinto del papel que la nación espera de nosotros. Queremos ser parte del país con ideas, con propuestas, con actitud universitaria; queremos estar a la altura de Bello, Letelier, Juvenal Hernández, Juan Gómez Millas. Queremos responder a un desafío que sentimos con fuerza proviene de nuestro interior. Queremos vivir la idea de "acomodo" que postuló Andrés Bello, y que significa una Universidad permeable al cambio y abierta a las demandas sociales. Queremos ser la Universidad de donde surja la propuesta para el debate en un campo tan delicado como el de la educación superior.

Nuestros esfuerzos estarán muy dedicados a llevar a cabo las acciones que demanda una agenda de cambio interno y de reposicionamiento externo. Trabajaremos con decisión y mucha unidad en la consecución de ese ideal de Universidad, con esa misión nacional y trascendente que define nuestro Proyecto Institucional a las puertas del siglo XXI. No descansaremos, y advertimos desde ya que nuestros pasos serán indetenibles en la preparación de nuestras propuestas institucionales, como asimismo en nuestra modernización interna y en la efectiva adopción del rol nacional, para que esta Universidad sirva efectivamente al Estado como un centro de reflexión y de creación, que un país que crece y se moderniza necesita en forma cada vez más evidente.

Señor Presidente, señoras y señores.

He recibido el respaldo de la comunidad académica para convertirme en el nuevo Rector. Ha ocurrido tras un debate de ideas muy propio de la Universidad de Chile, por su profundidad, su franqueza, su nivel y sus proyecciones. Creo que hemos dado una lección de democracia universitaria que no es casual. Este proceso ha puesto de manifiesto una labor efectuada en orden a recuperar una Universidad herida y con profundas huellas de dolor e insatisfacción. El Rector Jaime Lavados llevó a cabo esta labor, cuyos resultados sólo el paso del tiempo podrá revelar en toda su dimensión; más allá de las diferencias naturales que surgen en la vida académica cuando se debaten ideas -y que es tantas veces mal entendido y comunicado hacia el extramuro universitario- la labor efectuada permitió que la Universidad volviera a creer, se dio forma a la universidad que ahora tenemos para poder crecer en equilibrio, se sostuvo a una entidad que moría, con su alma dormida y afectada en su dignidad, su memoria institucional y su proyección en el tiempo. Más allá de cualquier juicio, la gestión del Rector Lavados ha permitido que estemos aquí, en un tránsito normal, con la ilusión y la esperanza de días aún mejores, con un proyecto que permita a las generaciones futuras tener un juicio más benévolo con respecto a lo que ha dejado la nuestra. Como se lo expresé en la última sesión del Consejo Universitario, quiero darle las gracias al ex-rector Dr. Lavados por su aporte, por su fuerza y convencimiento, y decirle que los Rectores de esta Casa nunca deben irse, sino permanecer en la continuidad permanente del cambio sobre el cambio, del acomodo infinito que nos dejara como tarea nuestro Andrés Bello.

Asumo la Rectoría en medio de un amplio sentimiento de reencuentro de nuestra comunidad universitaria, caracterizado por una sólida ilusión y el deseo de caminar juntos en una propuesta de cambio hacia fuera y hacia adentro. Luego del debate interno, hemos cerrado filas y estamos hoy todos tras el glorioso estandarte institucional. Estamos tras la idea de consolidar los nuevos organismos de Gobierno Universitario, y de dar forma al proyecto de Estatuto que aspiramos se convierta en una Ley para la Universidad de Chile. 
Llamo a trabajar con fuerza por el Proyecto Institucional que avizoramos. Llamo a deponer toda sombra de desconfianza o resquemor, para sustituirlo por la transparencia y la credibilidad. Llamo a mejorar cada día más en nuestro trabajo; a poner todo el empeño por salir adelante cada día mejor; por superar lo de ayer y esperar que lo de mañana nos supere con creces. Llamo a hacer Universidad con la fuerza de nuestra tradición, de nuestros valores, de nuestra misión. Somos los mejores... seguiremos siendo los mejores....advertimos que no cederemos en defender nuestra posición como la Universidad de Chile, la mejor, la gran referente, la de mayor brillo internacional, la con mayor compromiso con las tareas de país.

Siento una gran responsabilidad; una enorme distinción; un gran compromiso con el mandato que me han dado los académicos de la Universidad. Soy un fruto de la educación pública de Chile, desde la escuela primaria hasta la Universidad. Como educador siento en los rostros de nuestros niños y jóvenes, en sus esperanzas y sus manifestaciones, una señal muy clara sobre lo que se espera de esta gran Universidad, en las tareas que debemos dibujar para el futuro de esta gran nación, del legado que tenemos que dejar, acomodando nuestra situación a los cambios permanentes, pero también adelantando el cambio como lo hemos hecho a lo largo de la historia.

Se aproximan días de trabajo intenso, en que la comunidad toda deberá asumir la responsabilidad de construir el Proyecto Institucional que anhelamos. Yo pondré todas mis fuerzas, todo mi convencimiento, toda mi capacidad, para conducir esta grande y sublime barca por aguas tranquilas y tormentosas, pero buscando el arribo al puerto seguro que vislumbraron nuestros fundadores.

Agradezco este acto tan significativo, como asimismo la presencia de S.E. el Presidente de la República y de tantas autoridades de la nación. Lo veo como una señal de atención sobre esta histórica y querida institución, cuyo navegar infinito en el tiempo es, del mismo modo, el símbolo del progreso del país. Quiero entender que se nos está diciendo que importamos mucho, y que el Estado y la sociedad chilena seguirán sustentando su compromiso histórico y trascendente con esta Universidad, de Chile y para Chile.

Como siempre ha sido y como siempre ha de ser. 